\title{
Cultural Scripts in Narratives about Future Life: Comparisons among Japanese, Chinese and American Students ${ }^{1), 2)}$
}

\author{
Kumiko MUKAIDA ${ }^{3)}$ \\ Komazawa Women's Junior College \\ Lauren Shapiro CRANE \\ Wittenberg University
}

\author{
Hiroshi AZUMA \\ University of Tokyo
}

In this study, we explored cultural scripts in narratives about future life by comparing three different cultural groups. Participants were 236 Japanese, 83 Chinese, and 179 American undergraduates. They were asked to imagine and describe freely one day 10 years ahead. Through content analysis, we found that narratives about one's future life are likely to reflect scripts unique to each culture. Japanese narratives tended to be vague and to focus more on inner states. Chinese narratives were likely to contain concrete goals and behaviors, as well as aspirations. American narratives emphasized a nice job and a happy life with family. A "going with the flow" pattern, "mountain climbing" pattern and "happy ending" pattern were found to be dominant in Japan, China and the U.S., respectively. It is suggested that these culture-specific patterns are similar to the features of cultural texts prevailing in each society. Future research is needed to explore how these scripts emerge and how they influence people's behavior in reality.

Key words: cultural script, narrative, future life, content analysis

When we imagine how things will proceed in a

1) This research was supported by a Grant-in-Aid for Scientific Research (B-14310062) from the Japanese Society for the Promotion of Science and the Center of Developmental Education and Research to the second author.

2) The study reported here was included in Kumiko Mukaida's dissertation under the supervision of Hiroshi Azuma. We would like to thank Zhang Houcan, Xiaomin Sun, Jiang Wen, Li Zhongquan, and Tang Yun for their helping us collect data in China and develop a coding scheme. We are also grateful to Dan P. McAdams, Mari Maeda, Ai Miyagi, Izumi Uehara, and Fumiko Takasaki for their useful comments on a draft of this article.

3) Correspondence concerning this article should be sent to Kumiko Mukaida, Komazawa Women's Junior College, Sakahama, Inagi, 206-8511, Japan. (E-mail: k-mukaida@komajo.ac.jp) given situation, certain scripts are activated. For example, when going to a restaurant, we anticipate a series of actions based on an acquired script (Schank \& Ableson, 1977). Scripts are defined as "general event representation" (Nelson, 1981, p. 101) and "constitute the framework for interpretation, anticipation, judgment and evaluation of the actual process or story of the event" (Azuma, 2006, p. 316). Since scripts are learned from other people and cultural artifacts like books and TV, they tend to be shared among members of sociocultural groups. Thus, scripts are not necessarily universal but differ according to cultures (Azuma, 2006; Bruner, 1990; McAdams \& Pals, 2006). 
In order to explore scripts and cultural influences on them, we take a narrative approach because scripts are constituent elements of a narrative (Azuma, 2006; Bruner, 1990). More importantly, this approach is both nuanced and dynamic and therefore appropriate for capturing the uniqueness of each culture (Miller, 2002).

The present study aims to show that narratives about future life reflect scripts unique to each culture, and to identify the modal pattern of each script by comparing Japan, China and the U.S. Preceding studies (e.g., Mashima, Shapiro, \& Azuma, 1998; Crane, Maeda, \& Azuma, in preparation), which compared the U.S. with Japan using the same paradigm as this study, have found that a concrete and goal-oriented script was more favored by American undergraduates, whereas an ambiguous and process-oriented script was more often chosen by Japanese undergraduates. More specifically, when asked to imagine their future lives, the Americans tended to focus on details about their jobs and family lives, while the Japanese were more likely to mention their feelings and thoughts, including plans, hopes and worries. These findings suggest that cultural groups differ in the modal choice of scripts.

\section{Culture and Narrative Style}

Other cross-cultural studies have also shown that there are cultural differences in narrative style across a variety of genres such as folk tales (Kawai, 1982; Ozawa, 1999), prose (Kato, 2007), school textbooks (Tomo, Mashima, \& Nomoto, 1998) and media coverage (Markus, Uchida, Omoregie, Townsend, \& Kitayama, 2006). In addition to these cultural texts, individual narratives about moral reasoning (Azuma, 1994), explanation of events ( $\mathrm{Ji}$, Nisbett, \& Su, 2001; Miller, 1984; Watanabe, 2004), and recollection and prediction of life events (Mashima et al., 1998; Crane et al., in preparation) have also been found to vary depending on culture. Although most of these studies have made a limited comparison between the West (mostly the U.S.) and the East (mostly Japan), they suggest, in general, that Western narratives tend to highlight personal agency, means-end paths and linear processes, whereas Japanese narratives are likely to emphasize emotional states, time-sequential ordering or natural unfolding of events, and circular processes.

For instance, Western folk tales often have plots in which the protagonist meets an obstacle and takes action to solve problems with a successful outcome, for example, marriage. While resembling such Western stories in terms of basic elements and motifs, one archetype of Japanese folk tales, such as "The Crane Wife," involves a rather different plot: The protagonist has a fortunate encounter, as a result of which he finds happiness for a while, but eventually things return to their original state as if "nothing has happened" (Kawai, 1982, p. 32; Ozawa, 1999).

As for life stories, cross-cultural research seems scarce, yet some studies have found correspondence between individual narratives and cultural texts. For example, McAdams (2006) demonstrated that the themes of life stories narrated by Americans who are high in Erik Erikson's generativity resemble those in traditional American texts ranging from autobiographies to fiction. According to Plummer (1995), stories by sexual minorities in Western societies often contain the same five plots that Elsbree (1982) identified in modern Western novels, such as pursuing consummation. These findings strongly suggest that individual narratives would be constructed based on existing cultural texts and would tend to resemble each other within a given 
cultural group, while at the same time reflecting each individual's experiences.

\section{Narrative Identity and Future Life}

The major developmental task in adolescence is the formation of identity (Erikson, 1968). In terms of the development of narrative identity, it is suggested that the ability to tell a full life story emerges in late adolescence (Havermas \& Black, 2000; McAdams, 2006). In the process of searching for an identity, adolescents need not only to reflect on the past and create a coherent meaning of it, but to have a vision of the future and make plans for it realistically. In particular, college students are obliged to think about the future more seriously because they are soon to confront a major transition from school to the world of work and family after graduation.

Earlier studies on the future vision of college students cover a lot of ground (see Tsuzuki \& Shirai, 2007). For example, Tsuzuki (1999) revealed that future-orientation plays an important role in developing a sense of identity. He also found that Japanese female students tend to show a more relation-oriented perspective than their male counterparts. Markus \& Nurius (1986) argued that possible selves, defined as conceptions of the self in future states, function as incentives for future behavior and provide an evaluative and interpretive context for the current view of self. They indicated that possible selves considered by American undergraduates tend to be positively biased, making much of positive aspects and little of negative aspects of the self. This tendency, which is called self-enhancement, has been a robust finding among North Americans, but rarely among Asians (Heine, Lehman, Markus, \& Kitayama, 1999; Kitayama, Markus, Matsumoto, \& Norasakkunkit, 1997; Markus et al., 2006).

A cross-cultural study by Unemori, Omoregie, \&
Markus (2004) showed that whereas American undergraduates tended to depict possible selves as intrapersonal and interpersonal, those of Japanese and Japanese-American undergraduates were likely to center on career/education, suggesting that possible selves could be shaped by sociocultural context. Recent theorists have further suggested that possible selves have a narrative nature and could be better understood with a narrative approach (Erikson, 2007; Whitty, 2002). However, little research has been carried out so far focusing on the future vision of college students from both a narrative and cross-cultural perspective.

\section{Tricultural Comparison}

In this study, we examined narratives about future life in three different cultural groups: Japan, China and the U.S. One aim in selecting these groups was to ascertain if the previous findings on cultural scripts (Mashima et al., 1998; Crane et al., in preparation) would be replicated for Japanese and American students. A second aim was to extend the scope of the research to a tricultural comparison including China, in order to explore further cross-cultural variations in narrative scripts, especially in Asia. According to the conventional dichotomy of East versus West, Japan and China are reckoned as the same cultural group. Previous leading research has provided useful socio-psychological constructs like individualism-collectivism (Hofstede, 1980; Triandis, 1995) and independent-interdependent construals of the self (Markus \& Kitayama, 1991). In numerous cross-cultural studies based on these conceptual frameworks, Asians seem to respond quite similarly in various tasks, compared with Westerners (mostly North Americans) (e.g., Nisbett, 2003). Most studies, however, have compared one cultural group in the East and another in the West, 
without examining differences within the East or the West.

In fact, some empirical findings have demonstrated marked differences among Asian people from a narrative perspective. For example, exploring autobiographical memory in preschool children, Han, Leichtman, \& Wang (1998) found that Chinese and American children narrated their past experiences in a more voluminous way than Korean children. Crystal, Watanabe, Weinfurt, \& Wu (1998) reported that, when asked about human differences, Japanese and American children and adolescents responded similarly, compared to Chinese participants. In particular, Japanese and American participants mentioned more personality and demographic attributes and fewer behavioral characteristics than their Chinese counterparts. Another comparative study, although bicultural, confirmed that Chinese children were more likely to refer to overt behaviors than American children, who used more abstract descriptions, when describing themselves (Wang, 2006). Though the developmental stage of each sample was different, these findings suggest that Chinese narratives about themselves and other people would center on behaviors. In any case, studying two samples from Asia allows us to explore similarities and differences in Asian cultures and to make the research framework more exact and fine-grained.

Another reason for making a tricultural comparison in this study is to overcome the limitation of conventional cultural dichotomies. As Azuma (2003) noted, when simply contrasting one group with the other, especially in a cross-cultural context, differences between them tend to be emphasized, whereas similarities are likely to be underestimated. Thus, a bicultural comparison could entail increasing stereotypical views, if it were to place a strong emphasis on differences. Carrying out a multicultural comparison including at least three different groups is one way to decrease this risk by providing a more relative viewpoint.

Our study is rather exploratory and descriptive, especially for Chinese students, because there is scant research on narratives about future life from a cross-cultural perspective. However, on the basis of previous research which is available, we predicted that (a) American students would tend to articulate future visions of their job and family life compared to Japanese students; (b) Japanese students would be more likely to express feelings and thoughts than American students; (c) American students would focus more on positive aspects and less on negative aspects than the other two groups; (d) Chinese students would focus more on overt behaviors than the other two groups; and finally, (e) each cultural group would have a unique pattern of script in terms of what a future life should be.

\section{Method}

\section{Participants}

A total of 498 undergraduates participated in this study: 236 Japanese undergraduates (100 men and 136 women) from four different universities in Tokyo and one in Nagano, 83 Chinese undergraduates (41 men and 42 women) from two different universities in Beijing, and 179 American undergraduates (97 men and 82 women) from two different universities in Washington D.C. and Ohio. All American students had US citizenship. ${ }^{4)}$ Mean ages were 19.4 years $(S D=1.3)$ in Japan, 20.9 years $(S D=$

4) American students' ethnic backgrounds were as follows: $79.9 \%$ of the students $(N=143)$ were Caucasian, $5.6 \%(N=10)$ were Asian, $4.5 \%(N=8)$ were African-American, 2.8\% $(N=5)$ were Hispanic, and $5.0 \%(N=9)$ had multi-ethnic backgrounds. Four students did not indicate their ethnicity. 
1.7) in China and 19.0 years $(S D=0.9)$ in the U.S.

\section{Procedure}

All materials were originally developed in Japanese and then carefully translated into Chinese and English by bilingual collaborators in order to ensure linguistic equivalence. Participants were recruited through classes at the universities in each country and were paid for their participation. They took the questionnaire home and returned it at the end of one-week period, except for some of the U.S. students, who completed it in a group classroom setting. Data were collected during 2004 in Japan and China, and from 2006 to 2007 in the U.S.

The instruction was as follows: "Assuming that everything went pretty well, please imagine a typical weekday in October ten years from now. Please describe your whole day. What do you do, what do you think, and what do you feel?" Participants described their answers freely in the blank space below the instruction.

\section{Coding}

To begin with, both Chinese and English descriptions were translated into Japanese. Although a coding scheme for content analysis had originally been developed based on a pilot study in China and Japan and a previous study in the U.S. (Mashima et al., 1998), we modified it inductively in order to be as inclusive of all content as possible.

Table 1 Percentage of category mentions by cultural group

\begin{tabular}{|c|c|c|c|c|c|}
\hline Coding Category & $\begin{array}{l}\operatorname{Japan}(J) \\
(n=236)\end{array}$ & $\begin{array}{c}\text { China (C) } \\
\quad(n=83)\end{array}$ & $\begin{array}{l}\text { U.S. (U) } \\
(n=179)\end{array}$ & $\chi^{2}(2, N=498)$ & $\begin{array}{c}\text { post-hoc } \\
\text { comparison }\end{array}$ \\
\hline \multicolumn{6}{|l|}{ Daily life } \\
\hline surroundings & 29.2 & 30.1 & 52.0 & $24.7^{* *}$ & $(\mathrm{~J}, \mathrm{C})<\mathrm{U}^{* *}$ \\
\hline daily routine & 35.2 & 25.3 & 60.3 & $38.5^{* *}$ & $(\mathrm{~J}, \mathrm{C})<\mathrm{U}^{* *}$ \\
\hline \multicolumn{6}{|l|}{ Work } \\
\hline working & 83.5 & 98.8 & 95.5 & $25.1^{* *}$ & $\mathrm{~J}<(\mathrm{C}, \mathrm{U})^{* *}$ \\
\hline kind of job & 39.8 & 72.3 & 59.8 & $32.0^{* *}$ & $\mathrm{~J}<(\mathrm{C}, \mathrm{U})^{* *}$ \\
\hline achievement & 8.9 & 50.6 & 24.0 & $65.0^{* *}$ & $\mathrm{~J}<\mathrm{U}<\mathrm{C}^{* *}$ \\
\hline aspirations & 10.6 & 48.2 & 8.4 & $76.6^{* *}$ & $(\mathrm{~J}, \mathrm{U})<\mathrm{C}^{* *}$ \\
\hline behavior on the job & 19.9 & 84.3 & 34.1 & $111.3^{* *}$ & $\mathrm{~J}<\mathrm{U}<\mathrm{C}^{* *}$ \\
\hline \multicolumn{6}{|l|}{ Family and friends } \\
\hline partner & 61.9 & 47.0 & 81.6 & $34.7^{* *}$ & $(\mathrm{~J}, \mathrm{C})<\mathrm{U}^{* *}$ \\
\hline children & 43.2 & 31.3 & 45.3 & $4.8^{\dagger}$ & \\
\hline behavior for the family & 33.1 & 14.5 & 28.5 & $10.5^{* *}$ & $\mathrm{C}<(\mathrm{J}, \mathrm{U})^{* *}$ \\
\hline behavior with the family & 27.1 & 28.9 & 64.2 & $63.9^{* *}$ & $(\mathrm{~J}, \mathrm{C})<\mathrm{U}^{* *}$ \\
\hline parents/siblings & 9.7 & 18.1 & 16.2 & $5.5^{\dagger}$ & \\
\hline friendship & 13.1 & 21.7 & 33.5 & $24.7^{* *}$ & $\mathrm{~J}<\mathrm{U}^{* *}$ \\
\hline \multicolumn{6}{|l|}{ Feelings and attitude } \\
\hline positive feelings & 53.4 & 75.9 & 82.7 & $43.0^{* *}$ & $\mathrm{~J}<(\mathrm{C}, \mathrm{U})^{* *}$ \\
\hline negative feelings & 27.1 & 43.4 & 16.8 & $21.1^{* *}$ & $\mathrm{U}<\mathrm{J}<\mathrm{C}^{* *}$ \\
\hline positive attitude & 16.9 & 56.6 & 16.2 & $62.0^{* *}$ & $(\mathrm{~J}, \mathrm{U})<\mathrm{C}^{* *}$ \\
\hline \multicolumn{6}{|l|}{ Thoughts } \\
\hline past & 9.3 & 28.9 & 5.6 & $32.6^{* *}$ & $(\mathrm{~J}, \mathrm{U})<\mathrm{C}^{* *}$ \\
\hline future & 43.2 & 26.5 & 11.2 & $51.1^{* *}$ & $\mathrm{U}<\mathrm{C}<\mathrm{J}^{* *}$ \\
\hline work & 12.3 & 36.1 & 7.8 & $38.4^{* *}$ & $(\mathrm{~J}, \mathrm{U})<\mathrm{C}^{* *}$ \\
\hline family & 22.9 & 19.3 & 10.6 & $10.6^{* *}$ & $\mathrm{U}<\mathrm{J}^{* *}$ \\
\hline society & 3.4 & 20.5 & 1.7 & $42.0 * *$ & $(\mathrm{~J}, \mathrm{U})<\mathrm{C}^{* *}$ \\
\hline worries & 22.9 & 10.8 & 5.6 & $25.5^{* *}$ & $\mathrm{U}<\mathrm{J}^{* * *}$ \\
\hline
\end{tabular}

$\uparrow p<.10, \quad * * p<.01$ 
We ultimately created 22 coding categories, which were subsumed into five superordinate categories, specifically, daily life, work, family and friends, feelings and attitude, and thoughts (see Table 1).

Each participant's description was coded by two independent Japanese coders according to the coding scheme. One of the coders was the first author, and the other was a graduate student who had been trained to about $90 \%$ accuracy using samples previously coded by the first author. If there were one or more words or expressions that applied to a certain category in each description, coders assigned 1 to that category, otherwise 0 was automatically assigned. As categories were not mutually exclusive, coders could check from 0 to 22 categories per description. Each category and a few examples of responses that fit it are given below.

There were two categories in daily life: (a) surroundings (e.g., "it's pretty warm," "to live in NYC"), (b) daily routine (e.g., "to have breakfast," "to watch TV"). Work consisted of five categories: (a) working (e.g., "to go to work"), (b) kind of job (e.g., "a lawyer," "to teach history"), (c) achievement (e.g., "a successful worker," "as the CEO of a company"), (d) aspirations (e.g., "I will move up the ladder") and (e) behavior on the job (e.g., "to treat patients," "to attend the meeting"). Family and friends consisted of six categories: (a) partner (e.g., "with my wife," "to have a boyfriend"), (b) children (e.g., "with my kids"), (c) behavior for the family (e.g., "to prepare dinner for my family"), (d) behavior with the family (e.g., "to hang around with my family"), (e) parents/siblings (e.g., "to call my parents") and (f) friendship (e.g., "to meet up with my friends"). Feelings and attitude were classified into three categories: (a) positive feelings (e.g., "happy," "content"), (b) negative feelings (e.g., "discouraged," "anxious") and (c) positive attitude (e.g., "to work hard," "to do my best"). Thoughts were divided into six categories: (a) past (e.g., "to reflect on my life"), (b) future (e.g., "to consider what is ahead of me"), (c) work (e.g., "to think about how I can best benefit my clients"), (d) family (e.g., "to think about my family"), (e) society (e.g., "to consider what I can do for my country") and (f) worries (e.g., "I wonder if I'm on the right track").

The percentage rates of agreement between the two coders were $.84, .79$, and .91 in the Japanese, Chinese and American sample, respectively. Disagreements were resolved by the judgment of the first author.

\section{Results}

\section{Content}

Table 1 shows the percentage of students in each culture who mentioned a particular category. The extent to which the percentage rate differed for groups was tested using the $\chi^{2}$-test. If the omnibus $\chi^{2}$-test showed $p<.05$, post-hoc pairwise comparisons with Bonferroni correction $(\alpha=0.05 / 3=0.017)$ were applied. There were significant differences for all categories except two: children and parents/siblings reached only marginal significance.

Daily life. About half of American students described surroundings, including weather, place and scenery. Daily routine was also most likely to be mentioned by American students. Chinese and Japanese students mentioned neither surroundings nor daily routine as much.

Work. Almost $100 \%$ of Chinese and American students stated that they would be working in ten years, and $60-70 \%$ of them referred to the kind of job they would have. More than $80 \%$ of Japanese students also stated that they would work, but only $40 \%$ mentioned the kind of job, a result consistent with our predictions. Chinese responses were simi- 
lar to those of American students, rather than those of Japanese students, on this point.

Both achievement and aspirations were most frequently mentioned by Chinese students. American students mentioned achievement relatively more often than Japanese students. Chinese students described their behavior on the job far more often than did their American and Japanese counterparts, a result in line with our predictions.

Family and friends. As expected, American students more frequently described their partner and behavior with the family, compared to Japanese students. Chinese students were least likely to mention behavior for the family. As opposed to depictions of their work, Chinese students were no more likely than the other two groups to mention behaviors in their family life. Interestingly, references to friendship appeared more often in American descriptions than in Japanese descriptions.

Feelings and attitude. While positive feelings were more frequently expressed by both American and Chinese students than their Japanese counterparts, negative feelings were least frequently expressed by American students. These results, on the whole, accord with our predictions about positivity bias among American students. However, our predictions about frequent expression of feelings among Japanese students applied only to negative feelings, not to positive feelings. Positive attitude was much more likely to be expressed by Chinese students than by the other two groups.

Thoughts. Japanese students, as predicted, were more likely to mention thoughts overall than American students, especially thoughts on the future and family as well as worries. Chinese students also tended to mention thoughts, but the content was different: Compared to Japanese students, they more frequently expressed thoughts on the past, work and society, and less frequently mentioned thoughts on the future.

\section{Gender differences}

We examined gender difference for each category by using the $\chi^{2}$-test within each cultural group. Table 2 includes only the categories that reached statistical significance, specifically, 11 out of 24 categories in Japan, 1 in China and 6 in the U.S.

In the Japanese sample, four categories concerning work were more often mentioned by male students, whereas five categories regarding family and friends were more frequently mentioned by female students. In other words, Japanese male students were more likely to describe work situations and less likely to describe relationships than their female counterparts. In the Chinese sample, only thoughts on family were more frequently expressed by female students than male students. In the American sample, all six categories, including the kind of job, were mentioned more often by female students.

\section{Modal script patterns}

On the basis of content analysis, we tried to identify the modal script pattern in each cultural group. Japanese descriptions were likely to be vague, especially about working situations, as compared with those of the other two groups. Their descriptions also reflected traditional gender roles, namely, "men go to work and women stay at home." Japanese students tended to refer to general social roles rather than describe how they would behave in detail. They mentioned neither achievement nor behavior on the job as much as the other two groups. Instead, they most frequently expressed worries and thoughts about the future, which often emphasized the uncertain aspects of life (see Appendix). Taken together, Japanese students seemed to share a collective script expressing the view that life depends on the situation, and that what people can do is go 
Table 2 Percentage of category mentions by cultural group and gender

\begin{tabular}{|c|c|c|c|c|c|c|c|c|c|}
\hline \multirow[b]{2}{*}{ Coding category } & \multicolumn{3}{|c|}{ Japan } & \multicolumn{3}{|c|}{ China } & \multicolumn{3}{|c|}{ U.S. } \\
\hline & $\begin{array}{c}\text { Male } \\
(n=100)\end{array}$ & $\begin{array}{c}\text { Female } \\
(n=136)\end{array}$ & $\begin{array}{c}\chi^{2} \\
(1, N=236)\end{array}$ & $\begin{array}{c}\text { Male } \\
(n=41)\end{array}$ & $\begin{array}{l}\text { Female } \\
(n=42)\end{array}$ & $\begin{array}{c}\chi^{2} \\
(1, N=83)\end{array}$ & $\begin{array}{c}\text { Male } \\
(n=97)\end{array}$ & $\begin{array}{l}\text { Female } \\
(n=82)\end{array}$ & $\begin{array}{c}\chi^{2} \\
(1, N=179)\end{array}$ \\
\hline \multicolumn{10}{|l|}{ Work } \\
\hline working & 96.0 & 74.3 & $19.7^{* *}$ & 100.0 & 97.6 & 1.0 & 93.8 & 97.6 & 1.5 \\
\hline kind of job & 55.0 & 28.7 & $16.7^{* *}$ & 63.4 & 81.0 & $3.2^{\dagger}$ & 52.6 & 68.3 & $4.6^{*}$ \\
\hline aspirations & 16.0 & 6.6 & $5.4^{*}$ & 46.3 & 50.0 & 0.1 & 8.2 & 8.5 & 0.0 \\
\hline behaviour on the job & 26.0 & 15.4 & $4.0^{*}$ & 85.4 & 83.3 & 0.1 & 28.9 & 40.2 & 2.6 \\
\hline \multicolumn{10}{|l|}{ Family and friends } \\
\hline partner & 42.0 & 76.5 & $29.0^{* *}$ & 56.1 & 38.1 & 2.7 & 76.3 & 87.8 & $3.9^{*}$ \\
\hline children & 26.0 & 56.6 & $22.0^{* *}$ & 29.3 & 33.3 & 0.2 & 48.5 & 41.5 & 0.9 \\
\hline behavior for the family & 6.0 & 52.9 & $57.4^{* *}$ & 9.8 & 19.0 & 1.4 & 17.5 & 41.5 & $12.5^{* *}$ \\
\hline behavior with the family & 15.0 & 36.0 & $12.9^{* *}$ & 29.3 & 28.6 & 0.0 & 53.6 & 74.4 & $8.5^{* *}$ \\
\hline parents/siblings & 13.0 & 7.4 & 2.1 & 9.8 & 26.2 & $3.8^{\dagger}$ & 9.3 & 24.4 & $7.5^{* *}$ \\
\hline friendship & 7.0 & 17.6 & $5.7^{*}$ & 19.5 & 23.8 & 0.2 & 28.9 & 39.0 & 2.1 \\
\hline \multicolumn{10}{|l|}{ Feelings and attitude } \\
\hline positive feelings & 47.0 & 58.1 & $2.8^{\dagger}$ & 75.6 & 76.2 & 0.0 & 76.3 & 90.2 & $6.0^{*}$ \\
\hline negative feelings & 38.0 & 19.1 & $10.4^{* *}$ & 41.5 & 45.2 & 0.7 & 12.4 & 22.0 & $2.9^{\dagger}$ \\
\hline \multicolumn{10}{|l|}{ Thoughts } \\
\hline family & 14.0 & 29.4 & $7.8^{* *}$ & 7.3 & 31.0 & $7.4^{* *}$ & 7.2 & 14.6 & 2.6 \\
\hline
\end{tabular}

${ }^{\dagger} p<.10, \quad * p<.05, \quad * * p<.01$

with the flow, rather than trying to set high goals. We labeled this script metaphorically as a "going with the flow" pattern.

Chinese students were more likely to describe working situations in specific and concrete terms than were the other two groups, but they were less likely to mention family life. Chinese students stressed achievement and aspirations on the job, as well as positive attitudes needed to achieve high goals. Their descriptions also tended to include both positive and negative feelings (see Appendix). On the basis of these results, Chinese students seemed to possess a common script that saw life as somewhat difficult, like a high mountain to be climbed, but with much effort one could reach the top and make a success of one's life. We labeled this kind of script a "mountain climbing" pattern.

Most American students were positive about their future, in which they envisioned having a job and a family. Compared to the other two groups, Americans more often tended to articulate relationships with family and friends, as well as their daily life. They least frequently mentioned negative feelings and inner thoughts (see Appendix). Thus, American students seemed to share a cultural script that viewed life as merry and happy, the goal of which was to get a good job and have a nice family. We labeled this script a "happy ending" pattern.

To extract the culture-specific patterns of each group more directly, we created a new set of categories (Table 3). Each pattern's index is a composite of three or four indicators. For example, a going with the flow pattern needs to meet three indices: to describe that the student would be working, without mentioning any behavior on the job, and to express either worries or thoughts on the future.

Based on these indices, we calculated the extent to which each pattern appeared in each sample. As 
Table 3 Indices of modal patterns in narratives about future life

\begin{tabular}{|c|c|c|}
\hline Going with the flow & Mountain climbing & Happy ending \\
\hline working & working & working \\
\hline without behavior on the job & kind of job & married \\
\hline worries or thoughts on the future & behavior on the job & behavior with the family \\
\hline- & achievement or aspirations & positive feelings \\
\hline
\end{tabular}

a result, the going with the flow pattern made up $33.1 \%$ of the Japanese sample, whereas it made up only $8.4 \%$ of the Chinese sample and $5.6 \%$ of the American sample $\left(\chi^{2}(2, N=498)=57.05, p<.01\right)$. Post hoc tests confirmed each pattern as culturespecific $(p s<.01) .{ }^{5)}$ The mountain climbing pattern occupied $49.4 \%$ of the Chinese sample, but only $7.6 \%$ of the Japanese sample and $12.8 \%$ of the U.S. sample $\left(\chi^{2}(2, N=498)=80.55, p<.01\right)$. The happy ending pattern represented $48.0 \%$ of the American sample, but $13.6 \%$ of the Japanese sample and $22.9 \%$ of the Chinese sample $\left(\chi^{2}(2, N=498)=61.77\right.$, $p<.01)$. These results, shown in Figure 1, support our predictions. Gender differences were observed only in the happy ending pattern in the American sample: There were more happy ending patterns among American female students (59.8\%) than among their male counterparts (38.1\%), $\chi^{2}$ (1, $N=179)=8.32, p<.01$.

\section{Discussion}

Our five predictions were supported on the whole. Two out of five were fully supported: (a)

5) As the result of post-hoc pairwise comparisons with Bonferroni correction $(\alpha=0.05 / 3=0.017)$, we found that the going with the flow pattern was more prevalent in the Japanese sample than in the American and Chinese samples $(p<.01)$; the mountain climbing pattern was more widespread in the Chinese sample than in the American and Chinese samples $(p<.01)$; and the happy ending pattern was more predominant in the American sample than in the Japanese and Chinese samples $(p<.01)$.

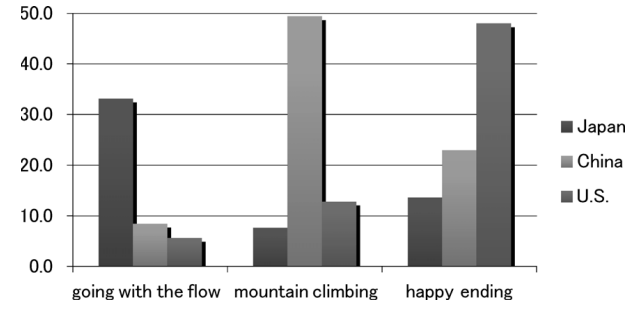

Figure 1 Percentage of each pattern of script by cultural group (\%)

American students tended to articulate future visions of their job and family life more often than Japanese students; and (e) each cultural group had a unique script pattern in terms of what a future life should be. The remaining three predictions were partially supported: (b) Japanese students were more likely than American students to express thoughts and negative feelings, but not positive feelings; (c) American students tended to mention negative aspects less frequently than the other two groups, and to mention positive aspects more frequently than Japanese students but not than Chinese students, and (d) Chinese students were more likely than the other two groups to focus on behaviors on the job, but not in their family life.

In all three cultures, work and family were two main elements of the narratives about future life. To get started in an occupation and to get married are major developmental tasks for college students during the next stage of life (Newman \& Newman, 1975). This result suggests that the contents of life narratives reflect general developmental tasks 
(Nurmi, 1992). However, the manner in which individuals fashioned narratives around these tasks seemed to be culture-specific, as discussed below.

\section{Goal-oriented vs. process-oriented}

Our findings generally replicated those of Mashima et al. (1998), despite some methodological differences. In particular, the American narratives contained more frequent and specific mentions of work and family and less frequent mentions of worries and thoughts on the future than did the Japanese narratives. Thus, it could be said that the American narratives tended to be concrete and goal-oriented, whereas the Japanese narratives were likely to be vague and process-oriented. As Heine et al. (1999) stated, "Japanese seem more concerned with the journey than the destination" (p. 771).

On the other hand, Chinese participants described their job even more concretely and ambitiously than did American participants. In fact, the Chinese narratives could be seen as being the most goal-oriented among the three groups. But they also appear to be process-oriented as well, because they tended to mention aspirations and positive attitudes, emphasizing the intention to "keep climbing a mountain." Thus, Chinese seem to regard a day ten years in the future as both a goal to be achieved and a step toward an even higher goal.

\section{Agency}

Agency is a key concept in psychology (Kagitcibashi, 2005; Markus et al., 2006). Given that Skinner (1996) defined "the self as agent, the self's actions or behaviors as the means, and effected change in the social or physical environment as the outcome" (p. 558), current concepts of agency integrate both overt behavior and outcomes (Bandura, 1989; Snibbe \& Markus, 2005). According to this definition, it seems that agency appeared clearly in the Chinese and American narratives, but only vaguely in the Japanese narratives, which contained less frequent mentions of goals and behaviors, compared to those of their Chinese and American counterparts.

Agency has sometimes been viewed as synonymous with control (Snibbe \& Markus, 2005). According to previous research on control (Weisz, Rothbaum, \& Blackburn, 1984; Morling \& Evered, 2006), "primary control" that seeks to influence the environment is dominant in the U.S., whereas "secondary control" that seeks to adjust the self and accept the environment is more prevalent in Asia. This assumption, however, seems to apply to our Japanese narratives, but not to our Chinese narratives. Insofar as "how to narrate" reflects "how to be" in each culture, our findings suggest that agency and its function vary in different parts of Asia.

\section{Relationships}

Relationships have often been construed as conflicting with individual agency (Bakan, 1966; McAdams, 2006). Cross-cultural research has shown that relationships are highly valued in collectivistic societies like Asia, while agency is stressed in individualistic societies like North America (Heine et al., 1999; Markus \& Kitayama, 1991; Triandis, 1995). In our study, however, relationships with partners and behaviors with family were more frequently mentioned in the American sample than in the Asian samples. In addition, references to friendship were more frequent in the American sample than in the Japanese sample. At first glance, these results seem contradictory to general conceptions of Western and East Asian cultures.

We speculate that establishing and keeping personal relationships would be experienced as an explicit task in American culture, where the individual is expected to be independent and separate, as Unemori et al. (2004) suggested. Some recent re- 
searchers contend that both agency and relatedness are basic human needs, and compatible with one another (Guisinger \& Blatt, 1994; Kagitcibashi, 2005). In fact, a meta-analytical review by Oyserman, Coon, \& Kemmelmeier (2002) has provided evidence that Americans are high in both individualism and relationality. On the contrary, in Asian cultures people might not need to declare that they have relationships, since the individual is inevitably relational. However, there is not sufficient evidence so far to draw any decisive conclusion on this point.

\section{Feelings and thoughts}

As reported earlier, Japanese cultural texts and individual narratives tend to focus on feelings and thoughts compared with those of Americans, which led us to the prediction that Japanese students would be more likely to express feelings and thoughts than American students. Our analyses supported this prediction, except for the mention of positive feelings, which were more frequently expressed by both American and Chinese participants.

These results could be explained by a positivity bias among Americans, as well as by emotional restraint among Japanese (Heine et al., 1999). It is suggested that Japanese childhood socialization places an emphasis on empathy (Azuma, 1994; Tsuneyoshi, 1992), but that the main focus is actually on reading other people's feelings, rather than on verbally expressing one's own feelings and ideas, which is conversely emphasized in both the U.S. and China (Tobin, Hsueh, \& Karasawa, 2009). This might help explain why the Chinese and American narratives tended to be more expressive of positive emotion than the Japanese narratives.

The mention of thoughts was relatively frequent among Japanese and Chinese participants, but rare among American participants. The Chinese narra- tives might be characterized as more socially-oriented, in that they tended to mention thoughts on work and society most frequently. On the contrary, the Japanese narratives would be characterized as more internally-oriented, in that they referred to worries and thoughts on the future most often. Again, these results suggest that narrative styles differ within Asia, as well as between the U.S. and Asia.

\section{Modal script patterns}

Finally, we successfully extracted modal script patterns for each culture: the "going with the flow" pattern in Japan, the "mountain climbing" pattern in China and the "happy ending" pattern in the U.S.

The "going with the flow" pattern was most prevalent among the Japanese narratives. Its vagueness and focus on inner states rather than specific goals and behaviors are consistent with previous findings on Japanese narrative, including traditional Japanese texts. This less agentic script pattern seems to reflect a greater emphasis on secondary control (Weisz et al., 1984) and a cognitive tendency to distribute one's attention more holistically when thinking about the cause and effect of events (Maddux \& Yuki, 2006; Markus et al., 2006). Both of these characteristics could make it difficult for participants to imagine the future in concrete terms. Furthermore, even if Japanese students can imagine the future concretely, a cultural tradition inhibiting grandiloquence might prevent them from narrating it as such.

The "mountain climbing" pattern was distinctive in Chinese narratives. It included concrete goals and behaviors as well as aspirations. This ambitious script pattern at least accords with earlier studies that demonstrated a strong will for academic and professional achievement among Chinese students (Japan Youth Research Institute, 1999; Salili, 1995; Stevenson \& Stigler, 1992), although there seems to 
be little evidence that such a pattern is reflected in traditional Chinese texts. It has been suggested that Chinese students' emphasis on achievement may be influenced by various factors, from parents' high expectations and pressure (Tobin et al., 2009) to the upward economic trend in Chinese society (McClelland, 1961). Moreover, Chinese participants narrated not a simple rags-to-riches story, but a more socially-oriented one, as discussed above.

The "happy ending" pattern was most common in the American narratives. It contained references to a nice job and a happy life with family, but few negative aspects. This optimistic script pattern is in line with previous research on the positivity bias (Markus \& Nurius, 1986) and an American emphasis on the pursuit of happiness (Heine et al., 1999; Tobin et al., 2009), as well as with features of traditional American texts, such as having a clear-cut ending (Kawai, 1982; Ozawa, 1999).

\section{Gender differences}

In the Japanese sample we found notable gender differences that reflected traditional gender roles. There also were significant differences by gender in the American sample, but for fewer categories. In the Chinese sample, gender differences reached significance only for thoughts on family. These results, especially for the Japanese, accord with previous findings indicating that women are more relationoriented (Gilligan, 1982; Greene \& DeBacker, 2004; Tsuzuki, 1999). The fact that female labor force participation is much higher in China and the U.S. than in Japan (World Economic Forum, 2008) suggests that the degree to which gender roles are expected and practiced in each culture may have an impact on narratives about future life. Additionally, in the case of the Americans, all six categories that reached significance were mentioned by female students more often than by male students. This re- sult could be partly explained by the fact that American females tend to be more verbal than their male counterparts (Kuebli, Butler, \& Fivush, 1995).

\section{Conclusion}

In this study, we found that narratives about future life were likely to reflect scripts unique to each culture. We suggest that these culture-specific scripts correspond to the features of traditional texts as well as individual narratives across a variety of themes in each culture. Future research is needed to explore how these scripts emerge, and how they influence people's behavior in reality.

We also found significant differences between the Japanese and Chinese narratives, as well as notable similarities and differences between the Chinese and American narratives. Although Asian societies are often regarded as the same collectivistic culture, this study strongly suggests that such a perspective does not always hold true. Adopting both a multicultural and narrative approach seems effective in exploring cross-cultural differences and similarities in a more nuanced way, compared to conventional methodologies that depend on cultural dichotomies.

\section{References}

Azuma, H. (1994). Nihonjin no shitsuke to kyoiku [Education and Socialization in Japan]. Tokyo, Japan: Tokyo University Press.

Azuma, H. (2003). A note on US-Japan comparison study: Cultural psychology and cross-cultural comparison. Human Developmental Research: Coder Annual Report, 17, 107-113.

Azuma, H. (2006). The era of fluid culture: Conceptual implications for cultural psychology. In Q. Jing, M. R. Rosenzweig, G. d'Ydewalle, H. Zhang, H.-C. Chen, \& K. Zhang (Eds.), Progress in psychological science around the world. Vol. 2. New York, NY: Psychology Press. pp. 305-318. 
Bakan, D. (1966). The duality of human existence. Chicago, IL: Rand McNally.

Bandura, A. (1989). Human agency in social cognitive theory. American Psychologist, 44, 1175-1184.

Bruner, J. S. (1990). Acts of meaning. Cambridge, MA: Harvard University Press.

Crane, L. S., Maeda, M. M., \& Azuma, H. (in preparation). And I live happily ever after: Conceptualizing the future self through American and Japanese narrative schemas.

Crystal, D. S., Watanabe, H., Weinfurt, K., \& Wu, C. (1998). Concepts of human differences: A comparison of American, Japanese and Chinese children and adolescents. Developmental Psychology, 34, 714-722.

Elsbree, L. (1982). The rituals of life: Patterns in narrative. Port Washington, NY: Kennikat.

Erikson, E. H. (1968). Identity: Youth and crisis. New York, NY: Norton.

Erikson, M. G. (2007). The meaning of the future: Toward a more specific definition of possible selves. Review of General Psychology, 11, 348-358.

Gilligan, C. (1982). In a different voice: Psychological theory and women's development. Cambridge, MA: Harvard University Press.

Greene, B. A., \& DeBacker, T. K. (2004). Gender and orientations toward the future: Links to motivation. Educational Psychology Review, 16, 91-120.

Guisinger, S., \& Blatt, S. J. (1994). Individuality and relatedness: Evolution of a fundamental dialectic. American Psychologist, 49, 104-111.

Han, J. J., Leichtman, M. D., \& Wang, Q. (1998). Autobiographical memory in Korean, Chinese, and American Children. Developmental Psychology, 34, 701-713.

Havermas, T., \& Black, S. (2000). Getting a life: The emergence of the life story in adolescence. Psychological Bulletin, 126, 748-769.

Heine, S. J., Lehman, D. R., Markus, H. R., \& Kitayama, S. (1999). Is there a universal need for positive self-regard? Psychological Review, 106, 766-794.

Hofstede, G. (1980). Culture's consequences. Beverly Hills, CA: Sage.

Japan Youth Research Institute. (1999). Daigakusei no syokugyo ni kansuru isiki chosa hokokusho: Nihonchugoku kokusai hikaku [A survey of career vision among college students: A comparison between Japan and China]. Tokyo, Japan: Author.

Ji, L-J., Nisbett, R. E., \& Su, Y. (2001). Culture, change, and prediction. Psychological Science, 12, 450-456.

Kagitcibashi, C. (2005). Autonomy and relatedness in cultural context: Implications for self and family. Journal of Cross-cultural Psychology, 36, 403-422.

Kato, S. (2007). Nihon bunka ni okeru jikan to kukan [Time and space in Japanese culture]. Tokyo, Japan: Iwanami Shoten.

Kawai, H. (1982). Mukashi banasi to nihonjin no kokoro [Folk tales and Japanese mentality]. Tokyo, Japan: Iwanami Shoten.

Kitayama, S., Markus, H. R., Matsumoto, H., \& Norasakkunkit, V. (1997). Individual and collective process in the construction of the self: Self-enhancement in the United States and self-criticism in Japan. Journal of Personality and Social Psychology, 72, 1245-1267.

Kuebli, J., Butler, S., \& Fivush, R., (1995). Mother-child talk about past emotions: Relations of maternal language and child gender over time. Cognition and Emotion, $\mathbf{9}$, 265-283.

Maddux W. W., \& Yuki, M. (2006). The "ripple effect": Cultural differences in perceptions of the consequences of events. Personality and Social Psychology Bulletin, 32, 669-683.

Markus, H. R., \& Kitayama, S. (1991). Culture and the self: Implications for cognition, emotion, and motivation. Psychological Review, 98, 224-253.

Markus, H. R., \& Nurius, P. (1986). Possible selves. American Psychologist, 41, 954-969.

Markus, H. R., Uchida, Y., Omoregie, H., Townsend, S. S. M., \& Kitayama, S. (2006). Going for the gold: Models of agency in Japanese and American contexts. Psychological Science, 17, 103-112.

Mashima, M., Shapiro, L., \& Azuma, H. (1998). A study on goal structure and future time perspective in composition tasks. Human Developmental Research: Coder Annual Report, 13, 106-118.

McAdams, D. P. (2006). The redemptive self: Stories Americans live by. New York, NY: Oxford University Press.

McAdams, D. P., \& Pals, J. L. (2006). A new Big Five: Fundamental principles for an integrative science of personality. American Psychologist, 61, 204-217.

McClelland, D. C. (1961). The achieving society. New York, NY: Free Press.

Miller, J. G. (1984). Culture and the development of everyday social explanation. Journal of Personality and Social Psychology, 46, 961-978. 
Miller, J. G. (2002). Bringing culture to basic psychological theory--beyond individualism and collectivism: Comment on Oyserman et al. (2002). Psychological Bulletin, 128, 97-109.

Morling, B., \& Evered, S. (2006). Secondary control reviewed and defined. Psychological Bulletin, 132, 269-296.

Nelson, K. (1981). Social cognition in a script framework. In J. H. Flavell, \& L. Ross (Eds.), Social cognitive development. Cambridge, UK: Cambridge University Press. pp. 96-118.

Newman, B. M., \& Newman, P. R. (1975). Development through life: A psychosocial approach. Oxford, UK: Dorsey.

Nisbett, R. E. (2003). The geography of thought. New York, NY: Free Press.

Nurmi, J. E. (1992). Age differences in the adult life goals, concerns, and their temporal extension: A life course approach to future-oriented motivation. International Journal of Behavioral Development, 15, 487-508.

Oyserman, D., Coon, H. M., \& Kemmelmeier, M. (2002). Rethinking individualism and collectivism: Evaluation of theoretical assumptions and meta-analyses. Psychological Bulletin, 128, 3-72.

Ozawa, T. (1999). Mukashi banashi no goho [Usage of folk tales]. Tokyo, Japan: Fukuinkan Shoten.

Plummer, K. (1995). Telling sexual stories: Power, change and social worlds. New York, NY: Routledge.

Salili, F. (1995). Explaining Chinese students' motivation and achievement: A socio-cultural analysis. In M. L. Maehr, \& P. R. Pintrich (Eds.), Advances in motivation and achievement. Vol. 9. Greenwich, CT: JAI Press. pp. 73-118.

Schank, R. C., \& Abelson, R. P. (1977). Scripts, plans, goals and understanding: An inquiry into human knowledge structures. Hillsdale, NJ: Lawrence Erlbaum Associates.

Skinner, E. A. (1996). A guide to constructs of control. Journal of Personality and Social Psychology, 71, 549-570.

Snibbe, A. C., \& Markus, H. R. (2005). You can't always get what you want: Educational attainment, agency, and choice. Journal of Personality and Social Psychology, 88, 703-720.

Stevenson, H. W., \& Stigler, J. W. (1992). The learning gap:
Why our schools are failing and what we can learn from Japanese and Chinese education. New York, NY: Summit Books.

Tobin, J., Hsueh, Y., \& Karasawa, M. (2009). Preschool in three cultures revisited: China, Japan, and the United States. Chicago, IL: University of Chicago Press.

Tomo, R., Mashima, M., \& Nomoto, T. (1998). A content analysis of interpersonal copining behavior in Japanese and British primary school textbooks. Japanese Journal of Educational Psychology, 46, 95-105.

Triandis, H. C. (1995). Individualism and collectivism. Boulder, CO: Westview Press.

Tsuneyoshi, R. (1992). Ningen keisei no nichibei hikaku [A U.S.-Japan comparison of human development]. Tokyo, Japan: Chuokoron-shinsha.

Tsuzuki, M. (1999). Daigakusei no jikanteki tenbo [Future time perspective of college students]. Tokyo, Japan: Chuo University Press.

Tsuzuki, M., \& Shirai, T. (Eds.) (2007). Jikanteki tenbo kenkyu gaidobukku. [Guidebook of research on future time perspective]. Kyoto, Japan: Nakanishiya Shuppan.

Unemori, P., Omoregie, H., \& Markus, H. R. (2004). Selfporraits: Possible selves in European-American, Chilean, Japanese and Japanese-American cultural contexts. Self and Identity, 3, 321-338.

Wang, Q. (2006). Culture and the development of selfknowledge. Current Directions in Psychological Science, 15, 182-187.

Watanabe, M. (2004). Nattoku no kozo: Nichibei syotokyoiku ni miru jiko hyogen no sutailu [The structure of reasoning: Styles of reasoning in Japanese and American primary education]. Tokyo, Japan: Toyokan Shuppansha.

Weisz, J. R., Rothbaum, F. M., \& Blackburn, T. C. (1984). Standing out and standing in: The psychology of control in America and Japan. American Psychologist, 39, 955-969.

Whitty, M. (2002). Possible selves: An exploration of the utility of a narrative approach. Identity: An International Journal of Theory and Research, 2, 211-228.

World Economic Forum. (2008). The global gender gap report 2008. Geneva, Switzerland: Author.

- 2009.11.20 受稿, 2010.6.22 受理一 
Appendix Examples of description of each cultural group

These are typical examples of future behaviors mentioned by students in each cultural group. The Japanese example is consistent with the "going with the flow" pattern; the Chinese example with the "mountain climbing" pattern; and the American example with the "happy ending" pattern.

Japanese male student: I will be working for a very ordinary private company but wondering if I should accept a position offered by another enterprise. Recently I met a friend from college who successfully started his own firm and I'm beginning to think about making a change instead of living life with no change. Yet, I am too busy to make any actual changes.

Chinese male student: On a day in October ten years from now, at eight o'clock in the morning in the laboratory, I will arrange all the material I need that day and I will start the outdoor observation at ten o'clock. At that time I will be holding the post of professor at the Vienna University in Austria while also being in charge of digital image processing and searching for resources in an energy development company. At ten o'clock I will get on a helicopter and will be looking down at Austria's green suburbs and the forest that are tens or more kilometers away. I will be recording the conditions of trees, water, air, and underground minerals with an observation measuring device. These will be my research data. I will be working and living in Vienna but at the same time I want to col- laborate with the Chinese government and conduct research and development work on resources in western China. It is not an exaggeration to say that I am a person who is not defeated in the face of difficulty and I don't mind suffering and pain. I want to establish a laboratory in western China and work there five days or more a month. After lunch I will return to the office at a little past one o'clock and summarize the data and resources. After 4 o'clock I will take a break. I am content with my life. My life does not have to be too brilliant. I like a modest, steady, and careful life.

American female student: My husband and I wake up in our home in the suburbs of Manhattan and eat breakfast. After getting dressed, I drive to the train station and take a crowded train into the city. When I get into the city, I walk up Park Avenue to the law firm that I own and manage. I think about all the goals I have accomplished and all the children I have helped through my focus on children's rights and I am proud and happy. After hours of work, I meet my sister for lunch and think about how much I value our friendship. I head back to work for a couple of hours and then head home. My husband and I cook dinner and eat while watching a movie that we've probably seen a hundred times. After cleaning up, we read or talk in bed for a while and then go to sleep, feeling extremely content. 